\title{
Risk Management of a Hydro Power Plant - Fracture Mechanics Approach
}

\author{
Ivana VUČETIĆ, Snežana KIRIN, Aleksandar SEDMAK, Tamara GOLUBOVIĆ, Mirjana LAZIĆ
}

\begin{abstract}
Risk management of a hydro power plant has been analysed from fracture mechanics point of view. The research is focused on the risk and integrity assessment of pressure equipment in a reversible hydro power plant in order to determine to what extent it poses a risk to Bajina Basta settlement and its inhabitants. The risk matrix has been used to assess risk level according to probability and consequence in a more descriptive way, whereas the failure assessment diagram has been used as an alternative engineering approach, including level II analysis.
\end{abstract}

Keywords: pressure vessel; reversible hydro power plant; risk management; settlement

\section{INTRODUCTION}

The improvement of electricity production and distribution introduced broader use of electricity, of which industrial use is the most prominent in relation to the general social development. The process of industrialization and influx of population triggered urban development, reflected in domain of economy, urban structure and urban activities, structure of population and quality of life. Electrification includes building of electric power plants based on diverse sources of primary energy used in process of electric energy production. Although their basic purpose is electrical energy production, being a complex system of specific functions, these power stations perform great impact on surrounding local area, [1]. Growing need for electrical energy, initiated building of power stations on bigger and bigger scale, not only in size, but also with increasing complexity. In that respect the risk degree and the possibility of technical equipment malfunction increase, as well as the scope of impact on surrounding area. This is the reason that in parallel with exploitation of power plant it is necessary to carry out continuous evaluation of possible extraordinary events and their consequences, as well as to define procedures for prevention of all negative effects. In order to minimize the risk of threatening the surrounding due to the irregularities in work process, it is necessary to carry out extensive maintenance of all technical systems of power plant, which implies constant monitoring of structural integrity and life of technical equipment involved in production process, regardless of the fact if it is in process of active use or not. The checkout of equipment condition implies periodical trial workstate, visual inspections and examination with nondestructive methods, including consultations with experts and specialized institutions.

As a consequence of industrialization, due to enlarged availability of electric power, economic and social development of Bajina Basta settlement went on in parallel with the opening of Hydro Power Plant (HPP) 'Bajina Bašta' in 1966 and its expansion, Reversible HPP (RHPP) in 1982. Taking into account possible negative consequences in the case of unwanted event, the highest impact level is related to integrity of the dam, drainage and pipelines and pressure vessels, as well as evacuation systems - (overflow) safety floodgate and foundation outlets. The rupture of the RHPP pipeline would cause water overflow of the surge hub in the surrounding area, escarpments of the nearby terrain and the collapse of the entire facility and local communications, which would be fatal for the local surrounding area. There are also irregularities in power plant exploitation and structure integrity malfunctions that do not cause severe consequences, as notable long-term damage of the environment, but due to their significantly higher frequency this should be as well the subject of constant examination and supervision. The broader scope of this research is the influence of RHPP, as a part of HPP Bajina Bašta on the development of Bajina Bašta settlement in terms of jeopardizing local surroundings and its inhabitants in case of realization of an unwanted event. In this paper, the research is focused on the risk and integrity assessment of pressure equipment in RHPP and strives to determine to what extent RHPP poses a threat to Bajina Basta settlement and its inhabitants. Toward this end, the fracture mechanics approach has been used to assess structural integrity of the RHPP, i.e. its most critical components, like pressure vessels for air storage. Having in mind relatively simple geometry, so-called engineering approach has been used, including the risk matrix analysis, [2-4]

\section{HPP BAJINA BASTA - GENERAL DESCRIPTION [3, 4]}

Reversable HPP "Bajina Bašta" operates within the HPP "Bajina Basta", Fig. 1, and represents the expansion of the existing plant, thus enhancing the energy characteristics of HPP "Bajina Basta" to the extent that they create a new modified plant with a very high flexibility, a high guaranteed power and a large amount of accumulated energy from hydroelectric power station. In order to fulfil all the abovementioned requirements, RHPP "Bajina Basta" must be always ready for operation. This means that at all times its generators must be technically ready for shifting to pump or generator operating modes, depending on the requirements of the Electric Power System.

The upper accumulation of the RHPP "Bajina Bašta" has very small tributaries that are naturally filled so that its operation depends on the operation of the pumps, that is, the operation of the generators in the pumping mode, which replaces the upper accumulation to later obtain electricity from the generating mode of the generator.

Because of the high power of the $310 \mathrm{MW}$ generator in the pumping mode, it is not possible to start the unit in the usual way of pumping the pumps. The generator is started by a synchronous "back to back" method. This means that it 
is powered by a generator of $105 \mathrm{MW}$ from the old HPP "Bajina Bašta". Since the generator has 3 times less power than the RHE pump that starts in the pump direction, it is necessary to create conditions for this start-up. The main condition is to push the water from the reversible aggregate impeller by blowing in air under pressure which must be available with a given volume and pressure at any moment.
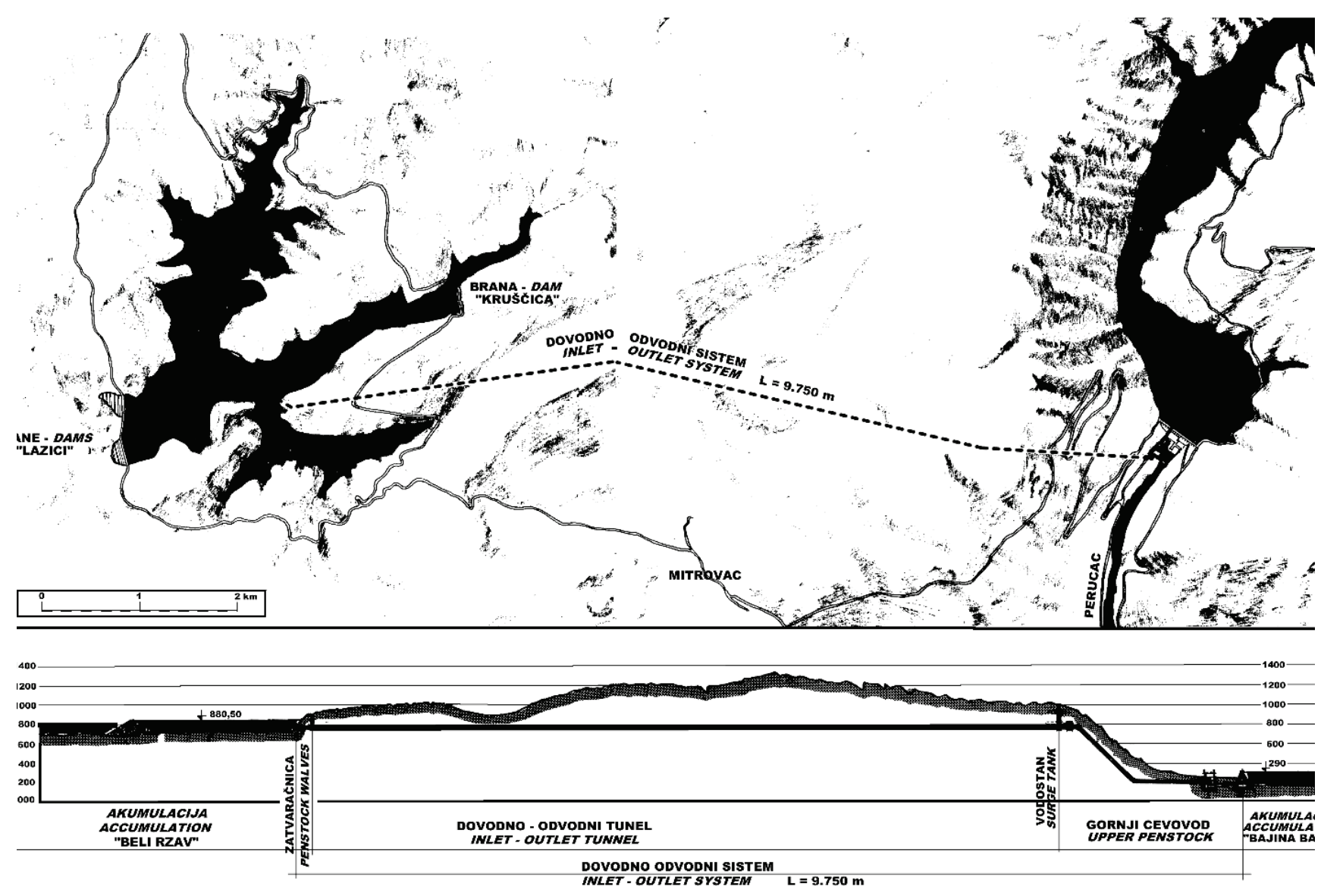

Figure 1 Upper and lower accumulation and inlet-outlet system of hydro power plant "Bajina Bašta" [5]

During the first internal examinations, spot corrosion was noticed on the interior surfaces of the tank No. 970 in which the compressor pressure tube was directly placed. The cause of corrosion is probably a compressed air system that enters a tank at a temperature of $50{ }^{\circ} \mathrm{C}$ and contains moisture from the air and acid caused by decomposition and combustion of the lubricating oil for the compressor during compression. Radiographic testing of welded joints was performed, finding unacceptable welding defects, [6, 7]. To obtain a permit for further use of the reservoir, it was necessary to hire a competent Institution to perform structural integrity. This was done by the University of Belgrade, Faculty of Mechanical Engineering, using the basic laws of fracture mechanics. Based on that report, the inspector signed the permission for further use of the tank with the recommendation to monitor the errors during periodic inspection of the equipment under pressure.

When observing the probability of an unwanted event, in this case, an explosion of compressed air reservoirs, what is noted is the intensity of possible consequences for the people, property, environment and reputation of the company. In the suggested model, we proposed a combination of qualitative and quantitative approach to the assessment of potential consequences, as given in Tab. 1 in the form of risk matrix, [7].

At the time of the explosion, everybody in the room would be affected by air strike, some probably fatally.
Compressor control equipment, and partly compressors, would be destroyed, as well as the part of the equipment for regulation and management of the hydro-aggregate $\mathrm{R} 1$, which is separated from the compressor station only by the overhaul door, which would be removed by force and thrown to the controller of the generator R1 due to the pressure in the room. Indirect damage would be the cost of total stoppage of RHPP, which is $180 \mathrm{~K} €$ /hour, taking into account the maximum load capacity at the price of $\mathrm{KWh}$ in europeak regime. After a breakdown, the power plant would not be able to operate in a pumping direction, which means that the undamaged generator R2 could only discharge the accumulated contents of the upper accumulation to a technical minimum, operating in the generator direction. Pumping would be disabled due to the lack of air pressure to start the pump unit, and without the pump there is no accumulation charging, or later generator operation.

The time for replacing the existing two reservoirs with three smaller tanks of a total volume of $3 \times 9 \mathrm{~m}^{3}$ would be minimum one month with previous thorough preparation of all transport details. Knowing that design and construction of new reservoirs lasts approximately one year, it is necessary to purchase three new reservoirs, as soon as possible, enabling urgent replacement if the analysis using fracture mechanics shows further inapplicability.

In accordance with risk analysis demonstrated here, the following was concluded, [4]: 
- Frequency estimation: there are incidents registered in relation to the explosion of pressure tank worldwide $\mathrm{B}$ - low risk level.

- Potential harmful consequences for people: it is possible for someone to get seriously injured or killed - 5B - medium risk level.

- Potential endangering impact on the environment is not registered - 1B - no risk.

- Potential damage to a company's reputation is estimated as 4B - medium risk level.

The overall risk level is defined as the highest registered risk level which in this case study amounts to $5 \mathrm{~B}$ (concerning people and property).
According to estimation of potential consequences of the unwanted event on the local surrounding area and its inhabitants, the case study demonstrated no impact on environment, but registered potential harmful impact of middle level risk degree on people's life and health and economy development related to damage to a company reputation. RHPP is a multiplex system, which consists of high-risk pressure equipment.

Anyhow, the aforementioned approach is a bit more descriptive than engineering. Therefore, now we introduce a special procedure for risk analysis, based on fracture mechanics concept, [8-11].

Table 1 Descriptive risk matrix, taken from [2]

\begin{tabular}{|c|c|c|c|c|c|c|c|c|c|}
\hline & \multicolumn{4}{|c|}{ Potential consequences } & \multicolumn{5}{|c|}{ Event frequency } \\
\hline & Poonlo & Dronorty & Environmont & Ponutotion & $\mathrm{A}$ & $\mathrm{B}$ & $\mathrm{C}$ & $\mathrm{D}$ & $E$ \\
\hline & People & Property & Environment & Reputation & Negligible & Low & Moderate & Medium & Large \\
\hline 0 & No injuries & No losses & No damage & No harm & & & & & \\
\hline 1 & $\begin{array}{l}\text { Insignificant } \\
\text { injuries }\end{array}$ & $\begin{array}{l}\text { Loss up to } \\
10 \mathrm{~K} €\end{array}$ & $\begin{array}{l}\text { Minor damage to } \\
\text { environment }\end{array}$ & $\begin{array}{l}\text { Insignificant } \\
\text { consequences. } \\
\text { Employees and } \\
\text { population } \\
\text { awareness. } \\
\end{array}$ & & & & & \\
\hline 2 & $\begin{array}{l}\text { Minor } \\
\text { injuries }\end{array}$ & $\begin{array}{l}\text { Loss from } \\
180 \mathrm{~K} € \text { to } \\
540 \mathrm{~K} €\end{array}$ & $\begin{array}{l}\text { Minor consequence } \\
\text { and damage to } \\
\text { environment. } \\
\text { Small costs. }\end{array}$ & $\begin{array}{l}\text { Mild } \\
\text { consequences. } \\
\text { There is a concern } \\
\text { at the local level. } \\
\end{array}$ & & & & & \\
\hline 3 & $\begin{array}{l}\text { Serious } \\
\text { injuries }\end{array}$ & $\begin{array}{l}\text { Loss from } \\
540 \mathrm{~K} € \text { to } \\
1,8 \mathrm{M} €\end{array}$ & $\begin{array}{l}\text { Moderate } \\
\text { consequence. } \\
\text { Short-term damage } \\
\text { to environment. }\end{array}$ & $\begin{array}{l}\text { Minor } \\
\text { consequences. } \\
\text { There is a concern } \\
\text { at the regional } \\
\text { level. }\end{array}$ & & & & & \\
\hline 4 & $\begin{array}{l}\text { Permanent } \\
\text { incapability }\end{array}$ & $\begin{array}{l}\text { Loss from } \\
1,8 \mathrm{~K} € \text { to } \\
50 \mathrm{M} €\end{array}$ & $\begin{array}{l}\text { Major conse- } \\
\text { quences. Big } \\
\text { damage to } \\
\text { environment. } \\
\text { Large costs. }\end{array}$ & $\begin{array}{l}\text { Moderate } \\
\text { consequences. } \\
\text { There is a concern } \\
\text { at the national } \\
\text { level. }\end{array}$ & & & & & \\
\hline 5 & Death & $\begin{array}{l}\text { Loss over } \\
50 \mathrm{M} €\end{array}$ & $\begin{array}{l}\text { Dire consequences. } \\
\text { Long-term and big } \\
\text { damage. } \\
\text { Huge costs. }\end{array}$ & $\begin{array}{l}\text { Dire consequence. } \\
\text { Concern and } \\
\text { reaction at the } \\
\text { international level. }\end{array}$ & & & & & \\
\hline
\end{tabular}

\section{FAILURE ASSESSMENT DIAGRAM}

Starting point in this analysis is the Failure Assessment Diagramme (FAD), as shown in Fig. 2. The FAD is based on simultaneous consideration of brittle fracture and plastic collapse, as to major mechanisms of failure of statically loaded steel structures, such as pressure vessels. Both failure mechanisms are represented as non-dimensional ratios of working parameters and material properties. In the case of brittle fracture, it is the ratio between stress intensity factor and fracture toughness, $K_{\mathrm{r}}=K_{\mathrm{I}} / K_{\mathrm{Ic}}$, whereas in the case of plastic collapse it is the ratio between net stress and critical stress, $S_{\mathrm{r}}=S_{\mathrm{n}} / S_{\mathrm{c}}$. Once these ratios are calculated, one can position the point on a diagram, which can be inside the safe area, or outside it, Fig. 2. The limit curve is defined according to Dugdale model, [12]:

$K_{r}=S_{r}\left[\frac{8}{\pi^{2}} \ln \sec \left(\frac{\pi}{2} S_{r}\right)\right]^{-\frac{1}{2}}$

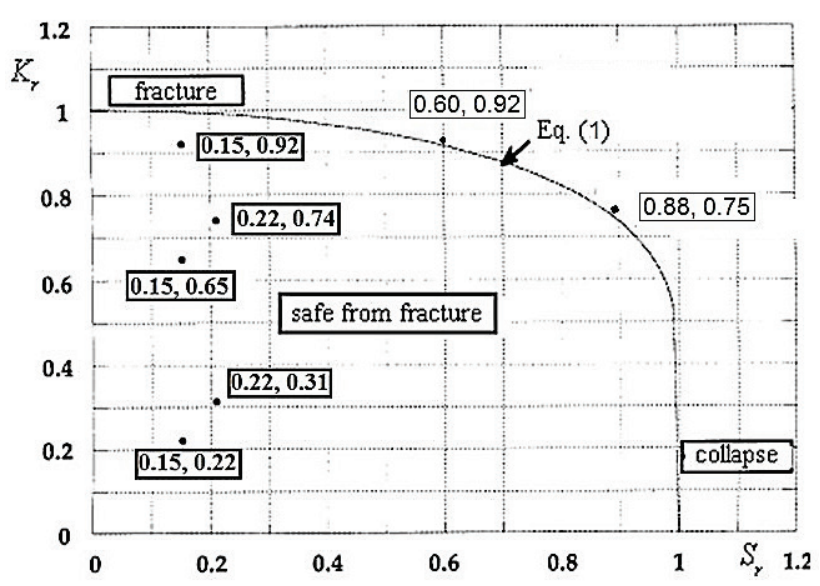

Figure 2 Failure assessment diagramme, [9], modified according to delamination (shifted points 1 and 4, as marked in Tab. 2)

This, classical fracture mechanics approach, has been used recently to estimate risk probability, [8-11], based on simple reasoning that the closer the point is to the limit curve the larger is the probability of failure. This approach was applied successfully in several cases of pressure vessels with detected cracks, including Pressure Vessels in RHPP BB, as shown in Fig. 2, taken basically from [9], but 
without shifted points: $(0.15,0.92)$ to $(0.6,0.92)$, and $(0.22$, $0.74)$ to $(0.88,0.74)$. These points basically took into account effects of residual stress (RS) and hydrostatic probe pressure ("over-pressure" - OP), as given in Tab. 2 and explained in [9], with additional shift due to delamination, the phenomenon explained in [13].

Table 2 Values for probabilities, [9]

\begin{tabular}{|l|c|c|c|c|c|c|}
\hline \multicolumn{1}{|c|}{ Point No. } & $\begin{array}{c}\text { Point Coord. } \\
(x ; y)\end{array}$ & $\begin{array}{c}K_{\mathrm{I}} \\
\mathrm{MPa} \sqrt{\mathrm{mm}}\end{array}$ & $K_{\mathrm{r}}=K_{\mathrm{I}} / K_{\mathrm{Ic}}{ }^{*}$ & $\begin{array}{c}S_{\mathrm{n}}=p R / 2 t \\
\mathrm{MPa}\end{array}$ & $S_{\mathrm{r}}=S_{\mathrm{n}} / S_{\mathrm{c}}{ }^{*}$ & $P_{\mathrm{fm}}$ \\
\hline 1. Crack with double length and RS & $(0,15 ; 0,92)$ & 1469 & 0,93 & 87 & 0,15 & 0,94 \\
\hline 2. Crack with real length and RS & $(0,15 ; 0,65)$ & 1038 & 0,66 & 87 & 0,15 & 0,70 \\
\hline 3. Crack with real length without RS & $(0,15 ; 0,22)$ & 345 & 0,22 & 87 & 0,15 & 0,24 \\
\hline 4. Crack with real length with RS withOP & $(0,22 ; 0,74)$ & 1186 & 0,74 & 124 & 0,21 & 0,84 \\
\hline 5. Crack with real length without RS with OP & $(0,22 ; 0,31)$ & 493 & 0.31 & 124 & 0,21 & 0,33 \\
\hline
\end{tabular}

As can be seen, Fig. 3, if "plastic" FAD is used the assessment points are still in the safe region. Let us also notice that relatively low $K_{\mathrm{I}}$ is a minor problem, because curve shifts right to the region where plasticity can sustain $S_{\mathrm{r}}$ larger than 1, Fig. 3, while relatively high $K_{\mathrm{I}}$ could present a major problem, at least according to the diagram, because the point would shift outside limit curve. Anyhow, this is theory, but in practice residual stresses, which are responsible for relatively high $K_{\mathrm{I}}$ value, probably would transform in plastic strain. Therefore, more sophisticated analysis is needed if residual stresses are significant, because FADs tend to be over-conservative.

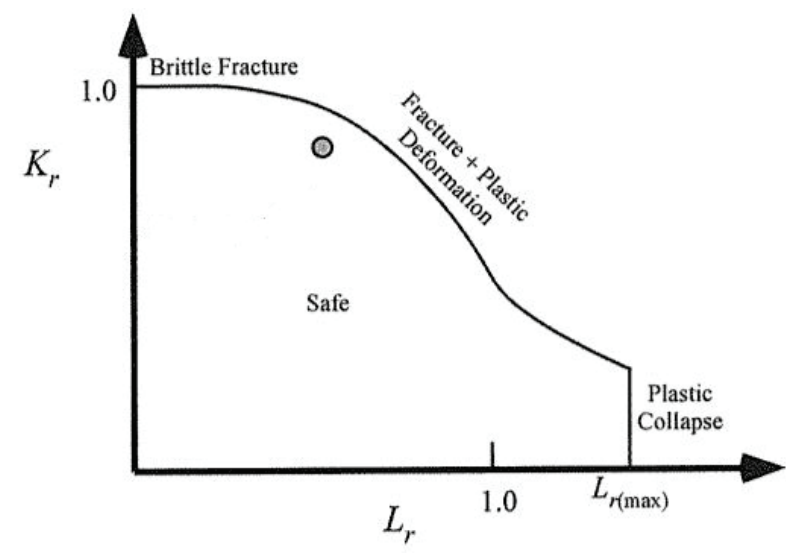

Figure 3 Failure Assessment Diagram

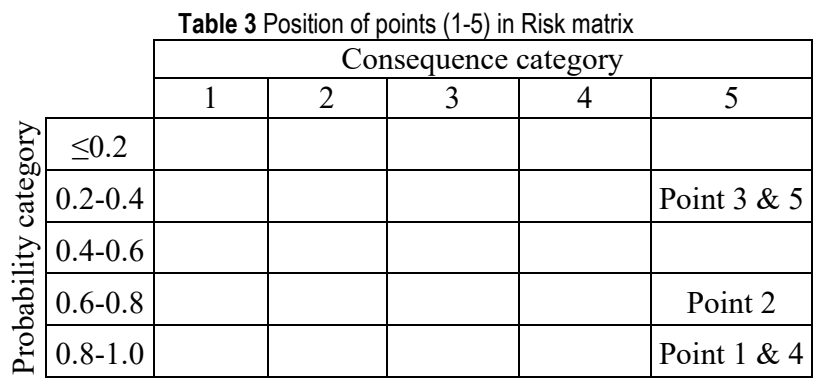

\section{RISK MATRIX AND RISK BASED ANALYSIS}

After defining probability, it is a simple matter to make the risk matrix, combining consequences with probabilities. According to the description given in table 1, explosion of the pressure vessel, considered here, corresponds to the category 5 , because of potentially catastrophic scenario, as defined in $[3,4]$. As one can see, points 1 and 4 have the highest risk, then comes point 2 , whereas points 3 and 5 have moderate risk. In this way one can follow influences of RS, $\mathrm{OP}$ and/or other factors. As an illustration, one can say that
OP shifts risk from high (point 2) to very high (point 4), indicating more detrimental than beneficial effect of OP.

\section{CONCLUSIONS}

It is shown, using different approaches, that the effect of RS is overestimated in "classical" FAD, even though it is not taken into account in evaluation of $S_{\mathrm{r}}$. Anyhow, its detrimental effect is more or less lost also for $K_{\mathrm{r}}$, if material is capable of plastic straining. This is the case with structural steels, including their weldments, even in the presence of cracks.

On the other hand side, detrimental effect of overpressure has been shown both by FAD and by using risk based matrix, combining probabilities, obtained by FAD, and consequences.

Finally, the effect of delamination has been also shown as detrimental, but only if it is simultaneous with other effects and large cracks. Future research should focus on more detailed analysis of interaction between all analysed effects, especially in the case of cold rolled steel plates used for old pressure vessel, since delamination in this case can make fatal contribution to catastrophic failure, as shown in [13].

\section{REFERENCES}

[1] Loo, T. \& Stanley, M. (2011). An Environmental History of Progress: Damming the Peace and Columbia Rivers. The Canadian Historical Review, 92, 399-427. https://doi.org/10.3138/chr.92.3.399

[2] Martić, I., Sedmak, A., \& Mitrović, N. (2019). Effect of over-pressure on pipeline structural integrity. Tehnički vjesnik, 26(3), accepted for publishing https://doi.org/10.17559/TV-20180708213323

[3] Vučetić, I. (2018). The impact of hydroelectric power station on development and modernization of Bajina Bašta settlement. Spatium, 39, 47-54 https://doi.org/10.2298/SPAT1839047V

[4] Vučetić, I., Kirin, S., Vučetić, T., Golubović, T., Sedmak, A. (2018). Analiza rizika u slučaju havarije rezervoara za vazduh u RHE Bajina Bašta. Structural Integrity and Life, 18, 3-6. (in Serbian)

[5] Sedmak, A., Sedmak, S., \& Milovic, Lj. (2011). Pressure Equipment Integrity Assessment by Elastic-Plasic Fracture Mechanics Methods. Monograph, Society for Structural Integrity and Life, Belgrade.

[6] Sedmak, A. \& Rakin, M. (2014). Application of Fracture Mechanics in Assessment of Structural Integrity. In Monograph (Eds. Sedmak, S. and Radakovic, Z.) "From Fracture Mechanics to Structural Integrity Assessment", IFMASS 8, Society for Structural Integrity and Life, Belgrade, 373-386. 
[7] Jovičić, R., Radaković, Z., Petronić, S., Dzindo, E., Jovičić $\&$ Bubalo, K. (2016). Inspection, non-destructive tests and repair of welded pressure equipment. Structural Integrity and Life, 16, 187-192.

[8] Stanojević, P., Jovanović, A., Kirin, S., Misita, M., Orlić, B., \& Eremić, S. (2015). Some achievements in RBIM implementation according to RIMAP approach. Structural Integrity and Life, 15, 79-84.

[9] Golubović, T., Sedmak, A., Spasojević Brkić, V., Kirin, S. \& Rakonjac, I. (2018). Novel Risk Based Assessment of Pressure Vessels Integrity. Tehnički vjesnik, 25(3), 803-807. https://doi.org/10.17559/TV-20170829144636

[10] Sedmak A., Algool, M., Kirin, S., Rakicevic, B., \& Bakic, R. (2016). Industrial safety of pressure vessels - Structural integrity point of view. Hemijska industrija, 70(6), 685-694. https://doi.org/10.2298/HEMIND150423005S

[11] Golubović, T., Sedmak, A., Spasojević Brkić, V., Kirin, S., \& Veg, E. (2018). Welded joints as critical regions in pressure vessels - case study of vinyl-chloride monomer storage tank. Hemijska industrija, 72(4), 177-182. https://doi.org/10.2298/HEMIND171009006G

[12] Anderson, T. (2003). Fracture Mechanics - Fundamentals and Applications, CRC Press.

[13] Mazur, A. (1994). Analiza loma visoko odgovornih Sistema pod pritiskom u rafineriji gasa. Monografija "Eksploatacijaske prsline u posudama pod pritiskom $i$ rezervoarima", TMF, Beograd, 261-292. (in Serbian)

\section{Contact information:}

Ivana VUČETĆ, PhD student

Innovation center of the Faculty of Mechanical Engineering,

Kraljice Marje 16, 11020 Belgrade 35, Serbia

\section{Snežana KIRIN, PhD}

Innovation Ccenter of the Faculty of Mechanical Engineering,

Kraljice Marije 16, 11020 Belgrade 35, Serbia

Aleksandar SEDMAK, Professor PhD

University of Belgrade, Faculty of Mechanical Engineering,

Kraljice Marije 16, 11020 Belgrade 35, Serbia

asedmak@mas.bg.ac.rs

Tamara GOLUBOVIĆ, PhD

University of Belgrade,

Faculty of Mechanical Engineering,

Kraljice Marije 16, 11020 Belgrade 35, Serbia

Mirjana LAZIĆ, PhD

University of Kragujevac, Faculty of Sciences,

Department of Mathematics and Informatics,

Radoja Domanovića 12, 34000 Kragujevac, Serbia 